\title{
Decomposition of process damping ratios and verification of process damping model for chatter vibration
}

\author{
Erol Turkes ${ }^{\mathrm{a}}$, Sezan Orak ${ }^{\mathrm{b}}$, Suleyman Neseli ${ }^{\mathrm{c}}$, Suleyman Yaldiz ${ }^{\mathrm{c}, *}$ \\ ${ }^{a}$ Dumlupınar University, Department of Mechanical Engineering, Tavsanli Yolu $10 \mathrm{Km}$, Kutahya, Turkey \\ ${ }^{\mathrm{b}}$ Eskisehir Osmangazi University, Department of Mechanical Engineering, Bati Meselik, Eskisehir, Turkey \\ c Selcuk University, Department of Mechanical Technologies, 42031 Konya, Turkey
}

\section{A R T I C L E I N F O}

\section{Article history:}

Received 21 October 2011

Received in revised form 24 February 2012

Accepted 20 March 2012

Available online 29 March 2012

\section{Keywords:}

Cutting tests

Workpieces materials

Model verification

\begin{abstract}
A B S T R A C T
In the previous study, by the same authors, titled "A new process damping model (PDM) for chatter vibration (Measurement, 44 (8) (2011) 1342-1348)", a new approach has been presented for obtaining process damping ratios (PDRs). This PDM has been constituted on the basis of the shear angle $(\varphi)$ oscillations of the cutting tool and the alteration of the penetration forces when they penetrate into the wavy surface. Variation and quantity of PDR are predicted by reverse running analytical calculation procedure of traditional Stability Lobe Diagrams (SLDs). In this study, firstly, how the PDM in previous study results with different materials such as AISI-1050 and Al-7075 are examined. Then, two problems are solved: how much of the total PDR of cutting system is caused by the tool penetration and how much is caused by $(\varphi)$ oscillation? Finally, verification of PDR values and PDM are performed by energy equations.
\end{abstract}

(c) 2012 Elsevier Ltd. All rights reserved.

\section{Introduction}

To obtain the final shapes of mechanical parts by turning operations are very important in present-day manufacturing. Examples of this metal cutting process can be found in the automotive, aerospace, and the mold and die industries [1]. However, one of the main factors limiting productivity in milling is the vibration of the system machine tool, spindle, tool holder, and tool, mainly due to a lack of dynamic stiffness. Regenerative chatter, a self excited vibration in operations where the tool cuts a previously machined surface, is the most common problem. The consequences are poor surface quality, inaccuracy, loud noise, excessive tool wear, machine tool damage, increased costs in terms of time, materials, and energy, and the environmental and economic impact of sanding marks, dumping

\footnotetext{
* Corresponding author. Tel.: +90 3322232349.

E-mail addresses: eturkes@dpu.edu.tr (E. Turkes),sorak@ogu.edu.tr (S. Orak), sneseli@selcuk.edu.tr (S. Neseli), syaldiz@selcuk.edu.tr
} (S. Yaldiz). non-valid final parts or repeating the metal removal operation [2].

Early research on chatter started with Taylor [3], Arnold [4] and Hahn [5] in the early part of the 20th century. Chatter was thought by some to be negative damping in the machining process [6] whilst others have more recently claimed that in the case of titanium milling the oscillation in forces as the result of segmented chip formation can initiate chatter [7], but is widely understood to be a function of the system dynamics and the cutting parameters [6,8].

A simple way to avoid regenerative chatter in machining is to select stable cutting conditions. A stability map can be generated, to show the combinations of width of cut and cutting speed where stable cutting conditions are found. Another successful strategy involves mitigation of chatter at lower surface speeds, utilizing process damping by tool-workpiece contact [9]. Most machining operations are conducted in low speeds (typically less than $300 \mathrm{~m} / \mathrm{min}$ ) range for hard materials, for instance titanium and nickel alloys. Certain operations take place in this range for softer materials also, e.g. grooving for 
carbon steels. When the tool or workpiece vibrates during cutting, waves are generated on the workpiece surface as a result [10].

Process damping force occurs in a section between tool cutting edge and wavy surface during the dynamic cutting. However, as it is not linear, the modeling of the process is still arduous and the basic subject matter has not fully been comprehended though it is recognized why and how this force is produced. The main subject of analytical calculation of process damping for chatter vibration is to research how and why the process damping occurs in chatter vibrations under low cutting speed conditions. Answers to those questions could not be found in the former research available in literature [11-14]. Since how the process damping affects the orthogonal cutting is not clearly understood, the additional effect of the process damping to the cutting system's structural damping could not be determined as well. In our previous study [15], a complex dynamic system is modeled prior to the orthogonal cutting which forms a mechanical cutting basis for all cutting processes in general. The complex dynamic system consists of dynamic cutting system force model which is based on the shear angle $(\varphi)$ oscillations and the penetration forces which are caused by the tool flank contact with the wavy surface. Static and Dynamic Cutting Force Coefficients (DCFCs) are obtained by using the dynamic cutting force model. Using these coefficients in the motion equations derived for the stability analysis increased the total PDR of the system. The complex PDM is developed through considering that it is derived from the shear angle $(\varphi)$ oscillations of dynamic cutting system and the penetration of tool to the wavy surface. PDR of the available cutting system are can be obtained by this complex PDM for different workpiece materials and cutting tools. Obtaining of the PDR values is achieved for the stability analysis in turning and milling conversely. Additionally the verification of PDM is analyzed after having found the total PDR with this procedure and how much is caused by tool penetration and how much by the alteration of cutting angle is found $[15,16]$. In this study, primarily the results of PDM with diversified materials such as AISI-1050 and Al-7075. The reason is to investigate according to what features of workpiece material the PDR changes.

\section{Process damping investigation from experimental results}

In this study, a system of orthogonal cutting was dealt with as a SDOF. Analytical modeling of this system and investigation of its stability were conducted in two different forms. The movement of the tool in dominant direction for SDOF system was considered because the natural frequency of the tool in another direction was very low in relation to the dominant direction. For this reason, it was accepted that the movement in this direction had no effect on stability limit of orthogonal cutting. Some simplifications were made in order to obtain a useful system model.

Values of natural frequency, stiffness coefficient and structural damping ratio $\left(\omega_{n}, k, \zeta_{\text {str }}\right)$ respectively are obtained by the modal analysis measurements and values of chatter frequency and stability maximum axial depth $\left(\omega_{c}, a_{\text {lim }}\right)$ respectively are obtained by cutting tests as given in Table 1. Modal parameters were determined by using a modal test, CutPro ${ }^{\circledR}$ MalTF software and CutPro ${ }^{\circledR}$ Modal software. These modal analysis measurements and cutting tests have been performed for AISI-1050 and Al-7075 workpiece materials whose diameter is $60 \mathrm{~mm}$ and tool attach lengths $L=70,90,110 \mathrm{~mm}$ the attach lengths of tool. The workpiece is cut by Kennametal (SDJR-2525M11 NA3) inserts on universal lathe TOS SN50C. Tool holder dimensions are $(b \times h \times l)=(25 \times 25 \times 110) \mathrm{mm}$. The modal analysis measurements are performed for measurement transfer functions of cutting systems. Measurement of transfer functions uses an impact hammer instrumented with a force transducer and an accelerometer attached to a machine tool structure (see Figs. 1 and 2). Diameter of the workpieces during the cutting tests has been reduced from $60 \mathrm{~mm}$ to $35 \mathrm{~mm}$.

Measurement of transfer functions of cutting systems have been performed for different available spindle speed $[\mathrm{rpm}]$ on machine tool and tool attach lengths $(L)$. Feed rate

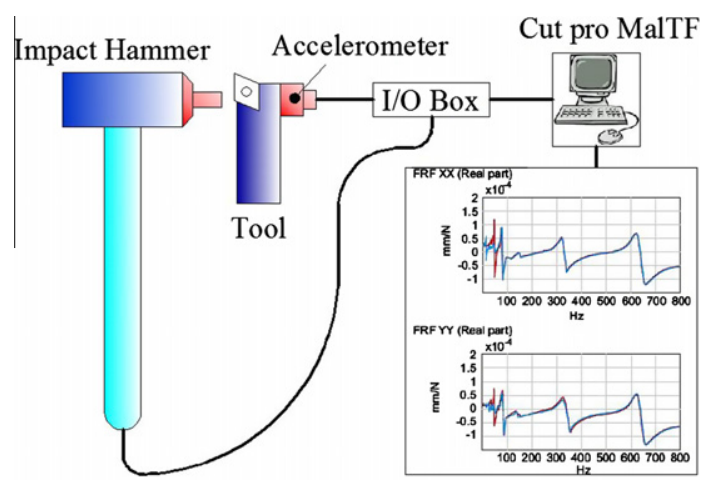

Fig. 1. Experimental setup for frequency response function (FRF) measurement.

Table 1

Modal analysis and chatter frequency values for AISI-1050 and Al-7075 materials.

\begin{tabular}{lllll}
\hline Tool length, $L(\mathrm{~mm})$ & Material & Natural frequency, $\omega_{n}(\mathrm{~Hz})$ & Stiffness, $k(\mathrm{~N} / \mathrm{m})$ & Damping ratio, $\zeta(\%)$ \\
\hline \multirow{2}{*}{70} & AISI-1050 & 1696 & $2.15 \times 10^{7}$ & $1.92 \times 10^{-2}$ \\
& Al-7075 & 1520 & $2.28 \times 10^{7}$ & $3.83 \times 10^{-2}$ \\
\multirow{2}{*}{90} & AISI-1050 & 944.6 & $5.71 \times 10^{6}$ & $4.15 \times 10^{-2}$ \\
& Al-7075 & 973.6 & $6.60 \times 10^{6}$ & $2.77 \times 10^{-2}$ \\
110 & AISI-1050 & 768.5 & $4.50 \times 10^{6}$ & $3.90 \times 10^{-2}$ \\
& Al-7075 & 732.5 & $4.53 \times 10^{6}$ & $1.43 \times 10^{-2}$ \\
\hline
\end{tabular}




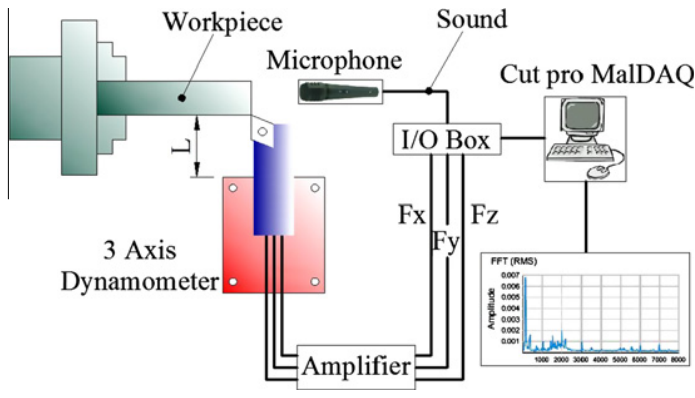

Fig. 2. Experimental setup for turning tests.

is $0.06 \mathrm{~mm} / \mathrm{rev}$ for all dynamic cutting tests. Maximum axial depths $\left(a_{\lim }[\mathrm{mm}]\right)$ of cut for chatter vibration-free machining are obtained from dynamic cutting tests by gradually increasing the cutting depths. Table 2 provides $\left(a_{\lim }\right)$ values in low and middle cutting speeds which obtained suitable spindle speed. Table 2 shows that when spindle speeds increase, the values of $\left(a_{\lim }\right)$ decrease since PDR decrease as well.

The dashed asymptotic curves in Figs. 3 and 4 are obtained by using the PDM that developed in values $[15,16]$ in Tables 1 and 2 . These asymptotic curves give stable cutting depths in different spindle speeds. The continuous asymptotic curves are plotted by using to $\left(a_{\text {lim }}\right)$ values of dynamic cutting tests. Also, the dashdot lines are plotted by using the known procedure for SLD in [17]. These dashdot lines define to minimum values of the lobes.

\section{Decomposition of process damping ratios}

PDR for stable spindle speeds and cutting depths of the cutting tests are total process damping ratios $\left(\zeta_{S T}\right)$ values of the dynamic cutting system. These $\left(\zeta_{S T}\right)$ values contain two different types of PDRs which occur by change of the shear angle $(\varphi)$ of cutting system and penetration volume $\left(V_{h}\right)$ of tool. Table 3 gives $\left(\zeta_{s T}\right)$ values for workpieces with AISI1050 and Al-7075 materials. These $\left(\zeta_{S T}\right)$ values have been obtained from the PDM in $[15,16]$.

If the total PDR $\left(\zeta_{s T}\right)$ values in Table 3 contain two different types of PDR which occur by changing the shear angle $(\varphi)$ of the cutting system and penetration volume $\left(V_{h}\right)$ of tool we can express as:

$\zeta_{s T}=\zeta_{s \varphi}+\zeta_{s p}$

where $\left(\zeta_{s \varphi}\right)$ occurs by changing the shear angle $(\varphi)$ of the cutting system, $\left(\zeta_{s p}\right)$ occurs by changing the penetration volume $\left(V_{h}\right)$ of tool. Also, total damping ratios $\left(\zeta_{T}\right)$ of the cutting system can be expressed as:

$\zeta_{T}=\zeta_{s t r}+\zeta_{s \varphi}+\zeta_{s p}$

where $\left(\zeta_{s t r}\right)$ is the structural damping ratio of the cutting system. Motion equations of the dynamic cutting system according to total damping ratio $\left(\zeta_{T}\right)$ or total damping coefficient $\left(c_{t}=2 \sqrt{\mathrm{km}}\right)$ of the cutting system can be expressed as Eq. (3) $[15,16]$ :

$$
\begin{aligned}
m_{x} \cdot \ddot{x}(t)+c_{t x} \dot{x}(t)+k_{x} x(t)= & -\tau_{s} a \lambda_{s x}\left(h_{0}-x(t)+x(t-\tau)\right. \\
& \left.+\lambda_{d x} \dot{x}-\lambda_{v x} \dot{y}\right) \\
m_{y} \ddot{y}(t)+c_{t y} \dot{y}(t)+k_{y} y(t)=- & \tau_{s} a \lambda_{s y}\left(h_{0}-x(t)+x(t-\tau)\right. \\
& \left.+\lambda_{d y} \dot{x}-\lambda_{v y} \dot{y}\right)
\end{aligned}
$$

where $\left(\tau_{s}\right)$ is the shear stress of workpiece $\left(\mathrm{N} / \mathrm{m}^{2}\right), \lambda_{s x}, \lambda_{s y}$, $\lambda_{d x}, \lambda_{d y}$ and $\lambda_{v x}, \lambda_{v y}$ are the static and dynamic cutting coefficients which can be determined from static cutting tests in [15], respectively. The open expressions of damping coefficient caused by the shear angle $(\varphi)$ oscillation included in the $\left(c_{t x, y}\right)$ total damping constant are described as follows:

$c_{\varphi x}=a_{\lim } K_{f} \lambda_{d x} ; \quad c_{\varphi y}=-a_{\lim } K_{t} \lambda_{v y}$

where $K_{t}$ and $K_{f}$ are tangential cutting force coefficient and the feed force coefficient $\left(\mathrm{N} / \mathrm{m}^{2}\right)$. The shear angle $(\varphi)$ oscillation could be investigated depending on the variation of cutting tool rake angle as in Fig. 5.

As it is seen on Fig. 5, when the tool vibration activity is considered as a sinusoidal curve, it will reach the maximum penetration bulk on $1 / 2$ period of activity. Accordingly, the slopes of tangents passing through a wave crest and vertical drop will be $(\delta=0)$. The slope of the wave midpoint of the tangent will be evaluated with ( $\delta=\max )$. As the slope rates on each point of the wave get minimal values compared to the speed of $(\dot{y}),\left(V_{0}\right)$, the expression could approximately be calculated with:

$\delta \cong \tan ^{-1}\left(\frac{\dot{x}}{V_{0}}\right)$

correlation. It is acquired from Fig. 5, through the equation of the rake angle alteration of the tool.

$\alpha_{i}=\alpha_{0}+\delta$

The value of $\left(r_{c 01}\right)$ rake thickness rates could be acquired from the formerly performed static cutting tests and rake thicknesses measured for various improvement rates in

\begin{tabular}{|c|c|c|c|c|c|c|c|c|}
\hline \multirow[t]{2}{*}{ Tool length, $L(\mathrm{~mm})$} & \multicolumn{8}{|c|}{ Spindle speed, $n$ (rpm) } \\
\hline & Material & 90 & 125 & 180 & 250 & 355 & 500 & 710 \\
\hline \multirow[t]{2}{*}{70} & AISI-1050 & 4.7 & 4.2 & 3.6 & 3.0 & 2.5 & 2.0 & 1.5 \\
\hline & Al-7075 & 7.8 & 7.0 & 6.3 & 5.5 & 4.8 & 4.0 & 3.5 \\
\hline \multirow[t]{2}{*}{90} & AISI-1050 & 4.0 & 3.5 & 3.0 & 2.4 & 2.0 & 1.5 & 1.1 \\
\hline & Al-7075 & 7.0 & 6.2 & 5.5 & 4.7 & 4.0 & 3.5 & 3.0 \\
\hline \multirow[t]{2}{*}{110} & AISI-1050 & 3.0 & 2.5 & 2.3 & 1.9 & 1.5 & 1.1 & 0.8 \\
\hline & $\mathrm{Al}-7075$ & 6.3 & 5.5 & 4.7 & 4.0 & 3.3 & 2.7 & 2.3 \\
\hline
\end{tabular}
accordance with work piece material. By this assumption,

Table 2

$\left(a_{\lim }(\mathrm{mm})\right)$ values for AISI-1050 and Al-7075 materials. 
(a)
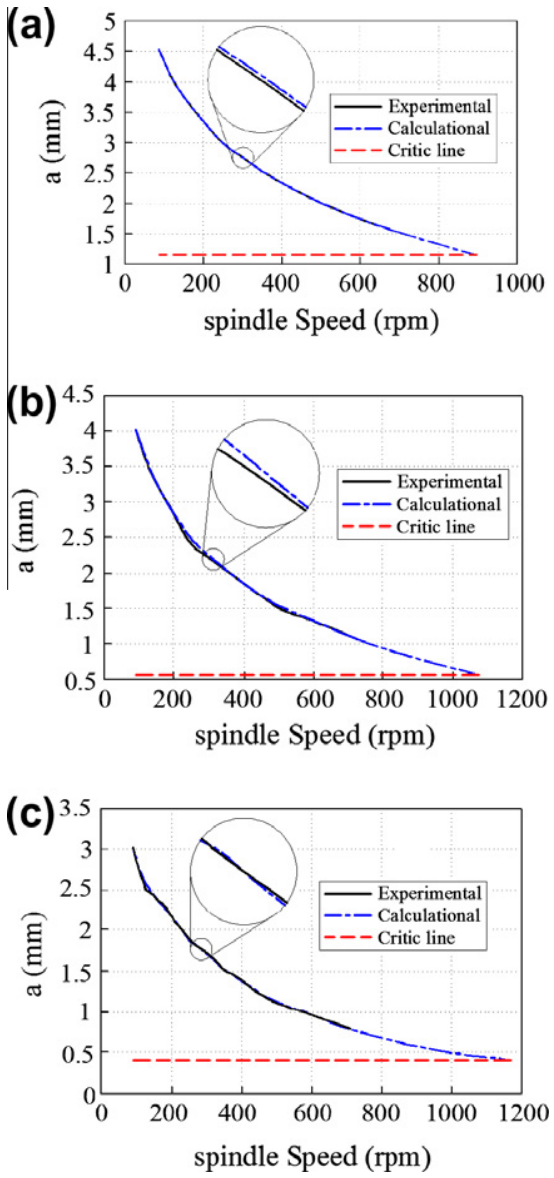

Fig. 3. SLD for attach lengths (a) $L=70$, (b) $L=90$ and (c) $L=110$ and AISI1050 .

as the shear angle for $(1 / 4)$ period of tool vibration will be as follows:

$\varphi_{0 i}=\tan ^{-1} \frac{r_{c 01} \cos \alpha_{i}}{1-r_{c 01} \sin \alpha_{i}}$

and as $(\delta)$ values will be the symmetric of the former half period for the other half period of the wave on the processed surface, $\left(\varphi_{0 i}\right)$ values will also be altered to symmetric. By this way, according to $\left(a_{\mathrm{lim}}\right)$ determined for various lower spindle speeds acquired by cutting tests in Eq. (4), $\left(\zeta_{s \varphi}\right)$ are obtained. Since the chatter frequencies obtained by cutting tests are constituted above the states of the natural frequency of the dynamic cutting system dominant mode, cutting system could be approved to be chattered on this dominant mode. Thus the dynamic cutting system could be assumed as a degree of freedom and gain $\left(\zeta_{s p}\right)$ values from Eq. (2). The decomposed $\left(\zeta_{S T}\right)$ values, acquired from various materials and conditions in Table 3 of this study and Table 3 of study $[15,16]$ are given in Table 4 .

Since the dominant mode on turning system will be in $(x)$ direction of the advancement of the dynamic cutting system, it is taken as $(\dot{y}(t) \cong 0)$ and could be written as follows:

$m_{x} \ddot{x}(t)+c_{t s x} \dot{x}(t)+k_{x} x(t)=F_{\text {esx }}(x(t)-x(t-\tau))$
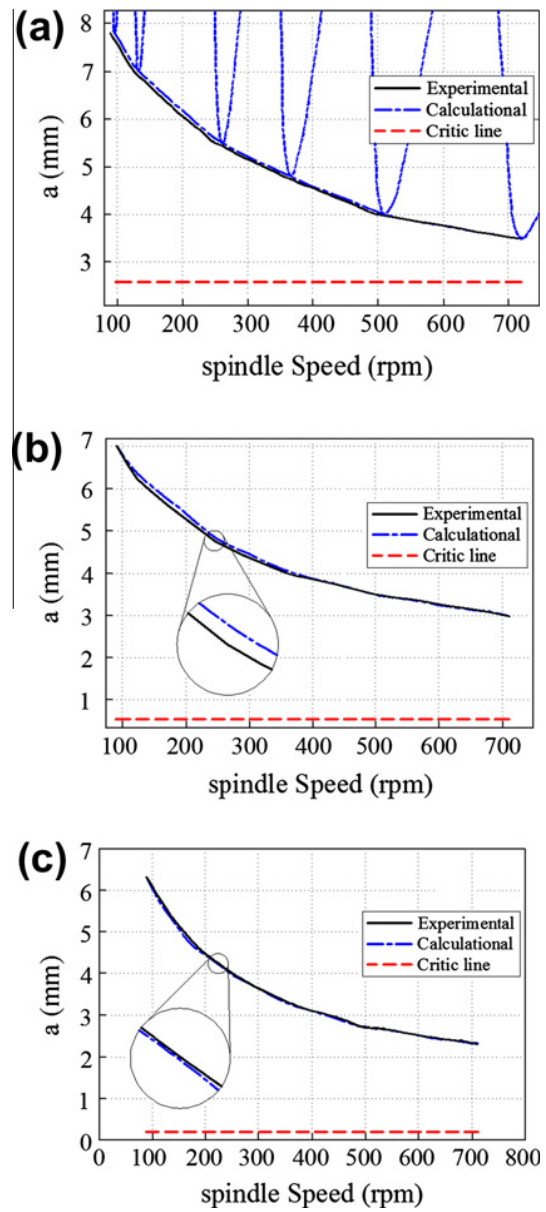

Fig. 4. SLD for attach lengths (a) $L=70$, (b) $L=90$ and (c) $L=110$ and Al7075.

Hereby $\left(c_{x}\right)$ is a value obtained by modal analysis tests and it is well known. The analysis of $\left(c_{\varphi x}\right)$ could be obtained through operating the procedure between Eqs. (5) and (7).

\section{Verification of process damping ratios}

The verification of PDR also means the verification of $\left(\zeta_{S T}\right)$ and PDM used for obtaining $\left(\zeta_{s \varphi}\right)$ and $\left(\zeta_{s b}\right)$ values that constitutes the total process damping. This verification process could be achieved through the verification of $(C)$ in Eq. (6) of [15]. The $(C)$ value is used for obtaining static and dynamic coefficients in $[15,16]$. Also, verification of specific cutting resistance constant $\left(f_{s p}\right)$ could be investigated by Eq. (26) of [15]. By this way both of the operation procedures that affect the forming of $\left(\zeta_{S T}\right)$ for stable cutting depths $\left(a_{\text {lim }}\right)$ should be verified. The energy equations between the tool-workpiece and equations of the developed PDM are used for this purpose. An energy production respectively occurs in the directions of $(X)$ and $(Y)$ by dynamic force components on the vibrating tool. The total energy of cutting system on both directions occurs than sum of ploughing $\left(E_{p x}, E_{p y}\right)$ and non-ploughing $\left(E_{x}, E_{y}\right)$ energies. These non-ploughing $\left(E_{x}, E_{y}\right)$ energies occur from the 
Table 3

Total PDR $\left(\zeta_{T}\right)$ values for workpieces with AISI-1050 and Al-7075 materials.

\begin{tabular}{|c|c|c|c|c|c|c|c|c|}
\hline \multirow[t]{2}{*}{ Tool length, $L$ (mm) } & \multicolumn{8}{|c|}{ Spindle speed, $n$ (rpm) } \\
\hline & Material & 90 & 125 & 180 & 250 & 355 & 500 & 710 \\
\hline \multirow[t]{2}{*}{70} & AISI-1050 & 0.1070 & 0.0950 & 0.0800 & 0.0644 & 0.0514 & 0.0380 & 0.0243 \\
\hline & Al-7075 & 0.0697 & 0.0595 & 0.0504 & 0.0400 & 0.0306 & 0.0197 & 0.0128 \\
\hline \multirow[t]{2}{*}{90} & AISI-1050 & 0.3000 & 0.2640 & 0.2300 & 0.1820 & 0.1500 & 0.1072 & 0.0711 \\
\hline & Al-7075 & 0.2605 & 0.2331 & 0.2083 & 0.1789 & 0.1521 & 0.1323 & 0.1120 \\
\hline \multirow[t]{2}{*}{110} & AISI-1050 & 0.3000 & 0.2430 & 0.2240 & 0.1852 & 0.1440 & 0.1000 & 0.0660 \\
\hline & Al-7075 & 0.3440 & 0.3100 & 0.2700 & 0.2300 & 0.2000 & 0.1630 & 0.1400 \\
\hline
\end{tabular}

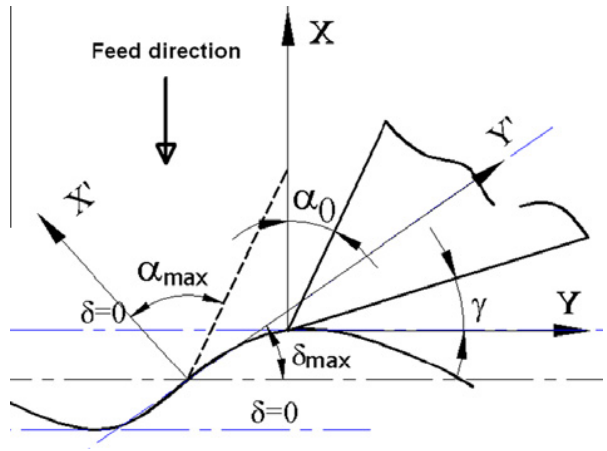

Fig. 5. The alteration of tool rake angle on wavy surface.

tool oscillation. These energies produced could be given together with the equations below:

$$
E_{x}=\int_{0}^{\frac{2 \pi}{\omega}}-F_{x} \dot{x} d t ; \quad E_{y}=\int_{0}^{\frac{2 \pi}{\omega}}-F_{y} \dot{y} d t
$$

$F_{x}$ and $F_{y}$ from Eqs. (3) and $[15,16]$, they are as follows:

$$
\begin{aligned}
& F_{x}=-a K_{f}\left[x(t)-x(t-\tau)+\lambda_{d x} \dot{x}(t)-\lambda_{v x} \dot{y}(t)\right] \\
& F_{y}=-a K_{t}\left[x(t)-x(t-\tau)+\lambda_{d y} \dot{x}(t)-\lambda_{v y} \dot{y}(t)\right]
\end{aligned}
$$

Here, benefiting from the trigonometric correlations they could be written as follows:

$x(t-\tau)=x(t) \cos \varepsilon-\left(\frac{\dot{x}(t) \sin \varepsilon}{\omega}\right)$

where $\omega$ is chatter frequency of the cutting system $(\mathrm{rad} / \mathrm{s})$. From Eqs. (10) and (11):

$F_{x}=F_{e s x} A_{x}\left[\sin \omega t-\sin (\omega t-\varepsilon)+\lambda_{d x} \omega \cos \omega t-\lambda_{v x}\left(\frac{A_{y}}{A_{x}} \omega \cos (\omega t+\psi)\right)\right]$
$F_{y}=F_{e s y} A_{x}\left[\sin \omega t-\sin (\omega t-\varepsilon)+\lambda_{d y} \omega \cos \omega t-\lambda_{v y}\left(\frac{A_{y}}{A_{x}} \omega \cos (\omega t+\psi)\right)\right]$

where $F_{\text {esx }}=-a_{\lim } K_{f}, F_{\text {esy }}=-a_{\lim } K_{t}, A_{x}$ and $A_{y}$ are amplitudes of the cutting tool on the $X$ and $Y$ directions respectively.
These amplitudes are obtained by time domain simulation as in $[15,16], \varepsilon$ is the phase shift between the inner and outer waves and $\psi$ is the phase shift of the structure's transfer function. On condition that they are substituted in Eq. (9), the energy equations could be reproduced on both directions arising from the tool oscillation, as follows:

$E_{x}=F_{e s x} A_{x}^{2} \pi\left[\sin \varepsilon+\lambda_{d x} \omega-\lambda_{v x} \frac{A_{y}}{A_{x}} \omega \cos \psi\right]$

$E_{y}=F_{e s x} A_{x} A_{y} \pi\left[(\cos \varepsilon-1) \sin \psi+\left(\lambda_{d y} \omega+\sin \varepsilon\right) \cos \psi-\lambda_{v y} \frac{A_{y}}{A_{x}} \omega\right]$

Considering the immersion of the tool, the calculation of ploughing energies arising from the ploughing could be expressed as follows:

$$
\begin{aligned}
E_{p x} & =-f_{c x} \Delta x_{i-k}=-\int_{0}^{\frac{2 \pi}{\omega}} f_{c x} \Delta \dot{x}_{i-k} d t ; \quad E_{p y}=-f_{c y} \Delta y_{i-k} \\
& =-\int_{0}^{\frac{2 \pi}{\omega}} f_{c y} \Delta \dot{y}_{i-k} d t
\end{aligned}
$$

Here, on condition that $\left(\frac{2 \pi}{\omega}\right)$ limit is taken as a sinusoidal curve on wavy surface of the tool, the tool will plough only on the half period of this curve. The total energy of the system on both directions will equate to sum of ploughing $\left(E_{p-}\right.$ $\left.{ }_{x}, E_{p y}\right)$ and non-ploughing $\left(E_{x}, E_{y}\right)$ energies.

$$
\begin{aligned}
& E_{t x}=E_{p x}+E_{x}=-\left(F_{x}+f_{c x}\right) x=-\int_{0}^{\frac{2 \pi}{\omega}}\left(F_{x}+f_{c x}\right) \dot{x} d t \\
& E_{t y}=E_{p y}+E_{y}=-\left(F_{y}+f_{c y}\right) y=-\int_{0}^{\frac{2 \pi}{\omega}}\left(F_{y}+f_{c y}\right) \dot{y} d t
\end{aligned}
$$

And as well, the total kinetic energy of the system is as follows:

$E_{k T}=\frac{1}{2} m \dot{x}^{2}=\frac{1}{2} m(L \omega)^{2}=E_{t x}+E_{t y}$

where $L$ is the attach length of the cutting tool ( $\mathrm{m})$. Thereby $\left(E_{x, y}\right)$ cutting energies, constituted from the cutting

Table 4

The decomposed PDR

\begin{tabular}{lllll}
\hline Spindle speed, $n(\mathrm{rpm})$ & Material & AISI-1050 & $\begin{array}{l}\text { Al-7075 } \\
\text { Tool length, } L(\mathrm{~mm})\end{array}$ & $\begin{array}{l}\text { AISI-1050 } \\
110\end{array}$ \\
\hline \multirow{2}{*}{90} & $\zeta_{s p}$ & 0.0290 & 0.2343 & 0.2800 \\
& $\zeta_{s \varphi}$ & 0.0034 & 0.0282 & 0.0240 \\
710 & $\zeta_{s p}$ & 0.1360 & 0.1000 & 0.0610 \\
& $\zeta_{s \varphi}$ & 0.0098 & 0.0125 & 0.0054 \\
\hline
\end{tabular}


Table 5

Comparison parameters of PDM.

\begin{tabular}{lllll}
\hline Material & $\begin{array}{l}\text { Material dependent } \\
\text { constant angle, } C\left(^{\circ}\right)\end{array}$ & $\begin{array}{l}\text { Specific resistance } \\
\text { of workpiece } \\
\text { material, } f_{s p}\left(\mathrm{~N} / \mathrm{m}^{3}\right)\end{array}$ & $\begin{array}{l}\text { Material dependent constant } \\
\text { angle corresponding to results } \\
\text { of the dynamic cutting tests, } C^{*}\left({ }^{\circ}\right)\end{array}$ & $\begin{array}{l}\text { Specific resistance corresponding } \\
\text { to results of the dynamic } \\
\text { cutting tests, } f_{s p}^{*}\left(\mathrm{~N} / \mathrm{m}^{3}\right)\end{array}$ \\
\hline AISI-1050 & 63.10 & $10.25 \times 10^{+9}$ & 63.04 & $10.35 \times 10^{+9}$ \\
Al-7075 & 69.83 & $4.60 \times 10^{+9}$ & 68.50 & $4.77 \times 10^{+9}$ \\
\hline
\end{tabular}

angle oscillation in Eq. (15) could be calculated together with the forces in Eq. (13) as follows:

$E_{x, y}=-F_{x, y} \Delta x, y$

Here, $(\Delta x)$ values for turning, and $(\Delta x, y)$ values for milling gain values up to the period of $(1 / 2)$ displaced of cutting tool as seen in Fig. 5. While obtaining the value of $\left(E_{x}\right)$ from Eq. (13), considering that the tool vibrates only in one mode (or dominant mode) during cutting, the equation becomes:

$E_{x}=F_{e s x} A_{x}^{2} \pi\left[\sin \varepsilon+\lambda_{d x} \omega\right]$

where $\left(A_{y}=0\right)$ of this equation is taken. Here it is taken as $F_{e s x}=a_{\lim } \tau_{s} \lambda_{s x}[15,16]$. By this way, Eqs. (17) and (18) could be written as:

$E_{x}=-F_{e s x} \Delta x$

Here, the stable cutting depths $a_{\lim }$ in $\left(F_{\text {esx }}\right)$ term are determined by cutting tests, $\lambda_{s x}$ constants that obtained than $\left(F_{\text {esx }}\right)$ term, according to $a_{\mathrm{lim}} \cdot \tau_{s}$ is the shear stress of workpiece and constants. Thereby, $\left(E_{x}\right)$ and $\left(E_{p x}\right)$ values are numerically obtained from the force equations and the energy Eqs. $(12,19,15)$, and (16) for corresponding $a_{\lim }$ and $\omega$ values which are obtained by dynamic cutting tests.

Through using static and dynamic cutting coefficients, $\left(C^{*}\right)$ is the material constant angle corresponding to results of the dynamic cutting tests and constant value, which is necessary for the research of verification of the PDM. These values of $\left(C^{*}\right)$ are compared with $(C)$ values which are formerly calculated. In the feed direction, $\left(\lambda_{s x}\right)$ static cutting coefficient is written as follows:

$\lambda_{s x}=\frac{\sin \left(C^{*}-2 \varphi_{0}\right)}{\sin \varphi_{0} \cos \left(C^{*}-\varphi_{0}\right)}$

Hence, the material constant term corresponding to results of the cutting tests could be written as:

$C^{*}=\cos ^{-1}\left(\frac{\sin \left(\beta_{n 0}\right)}{\lambda_{s x} \sin \left(\varphi_{0}\right)}\right)+\varphi_{0}$

By this way, the specific cutting resistance constant shall be verified for the research for the verification of the calculation procedure. For that purpose, once $\left(f_{c x, y}(t)\right)$ is found in the energy Eq. (14) for $a_{\lim }$ and $\omega$ values which are obtained by cutting tests. The comparison values of $\left(f_{s p}^{*}\right)$ from Eq. (26) in [15] could be obtained as follows:

$f_{s p}^{*}=\frac{f_{c x}(t)}{V_{h}}$

In other words, $\left(f_{s p}^{*}\right)$ is the specific resistance $\left(\mathrm{N} / \mathrm{m}^{3}\right)$, value of the $\left(V_{h}\right)$, which is the penetration volume to wavy surface of cutting tool $\left(\mathrm{m}^{3}\right)$, could be obtained as it is de- scribed in [15] and Lee et al. [11]. For each workpiece material used in the cutting tests for this study, the comparison parameters are given in Table 5 .

\section{Conclusions}

When investigating the results of this study firstly, Table 2 shows that $\left(a_{\lim }\right)$ values decreases by decrease of spindle speed and increase of attach length of cutting tool $(L)$. Additionally, it shows that $\left(a_{\lim }\right)$ values increase by decrease hardness of the work pieces. After, total PDR values $\left(\zeta_{T}\right)$ for various attach length of cutting tool and cutting speeds are obtained by reverse running analytical calculation procedure of traditional SLD. Table 3 shows that $\left(\zeta_{T}\right)$ increases through increase of attach length of cutting tool and decrease of spindle speed. In that case, the waves on surface of workpiece become sharply pointed by wavelength decreasing according to $\left(L_{w}=n(\mathrm{rpm}) / \Omega_{c}(\mathrm{~Hz})\right)$ equation. Accordingly, as the $\left(\zeta_{s p}\right)$ values increase, $\left(\zeta_{T}\right)$ increases as well which can be observed from Table 3 . Besides it appears that the greatest factor in process damping $\left(\zeta_{s p}\right)$ derives from penetration of the tool into the workpiece when $\left(\zeta_{T}\right)$ in presented PDM are taken into account just like the way in Eq. (2) and through decomposing the process damping rates, as in Table 4 . The value of $\left(\zeta_{s \varphi}\right)$ is approximately $1 / 10$ of $\left(\zeta_{s p}\right)$ value. The verification of $\left(\zeta_{s \varphi}\right)$ and $\left(\zeta_{s p}\right)$ is determined through investigation the verification of experimental methods and calculation procedure of dynamic cutting model, as in Table 5. The verification of PDR is also proved by plotted of SLD calculational and experimentally. In order to obtain more convenient PDM form this developed PDM shall be attempt to different materials and tools. By this way, for more diversified conditions, the PDR values could be predicted and SLD could be plotted more accurate.

\section{References}

[1] Norberto Lopez de Lacalle, Aitzol Lamikiz Mentxaka (Eds.), Machine Tools for High Performance Machining, vol. XXII, Springer, Second Printing, 2009, 442 p (300 illus.).

[2] G. Quintana, F.J. Campa, J. Ciurana, L.N. Lopez de Lacalle, Productivity improvement through chatter-free milling in workshops, Proc. IMechE Part B: J. Eng. Manuf. (2011).

[3] F.W. Taylor, On the art of cutting metals, Trans. ASME 28 (1907) 31350.

[4] R.N. Arnold, The mechanism of tool vibration in cutting of steel, Proc. Inst. Mech. Eng. 154 (1946) 261-284.

[5] R.S. Hahn, Metal-cutting chatter and its elimination, Trans. ASME 75 (1953) 1073-1080.

[6] G. Tlusty, Analysis of the state of research in cutting dynamics, Ann. CIRP 27 (1978) 583-589.

[7] Y. Ashiura, H. Motonishi, Titanium processing technology I, machining, Titanium Zirconium 35 (3) (1987) 131-141. 
[8] S. Smith, J. Tlusty, Update on high-speed milling dynamics, Trans. ASME J. Eng. Ind. 112 (1990) 142-149.

[9] J. Tlusty, Manufacturing Processes and Equipment, Prentice Hall, New Jersey, USA, 2000.

[10] C.M. Taylor, N.D. Sims, S. Turner, Process damping and cutting tool geometry in machining, in: Trends in Aerospace Manufacturing 2009 International Conference, IOP Conf. Series: Materials Science and Engineering, vol. 26, 2011, p. 012009.

[11] B.Y. Lee, Y.S. Tarng, S.C. Ma, Modeling of the process damping force in chatter vibration, Int. J. Mach. Tools Manuf. 35 (1995) 951-962.

[12] B.E. Clancy, Y.C. Shin, A comprehensive chatter prediction model for face turning operation including tool wear effect, Int. J. Mach. Tools Manuf. 42 (2002) 1035-1044.
[13] Y. Altintas, M. Eynian, H. Onozuka, Identification of dynamic cutting force coefficients and chatter stability with process damping, Manf. Technol. CIRP Ann. 57 (2008) 371-374.

[14] R. Rahnama, M. Sajjadi, S.S. Park, Chatter suppression in micro end milling with process damping, J. Mater. Process. Technol. 209 (2009) 5766-5776.

[15] E. Turkes, S. Orak, S. Neseli, S. Yaldiz, A new process damping model for chatter vibration, Measurement 44 (8) (2011) 1342-1348.

[16] E. Turkes, Theoretical and experimental analysis of process damping in machine tool chatter vibration, Ph.D. Thesis, University of Osmangazi, Eskisehir, Turkey, 2007.

[17] Y. Altintas, Manufacturing Automation; Metal Cutting Mechanics, Machine Tool Vibrations and CNC Design, Cambridge University Press, New York, 2000. 